\title{
Public Transport in Pakistan: A Critical Overview
}

\author{
Muhammad Imran \\ Massey University, New Zealand
}

\begin{abstract}
Urban transport problems in Pakistan are managed by building larger and better roads. By contrast, the principles of sustainable transport encourage using lowcost public transport that could perform well in mixed land use and high density Pakistani cities. The purpose of this paper is to provide a critical overview of public transport policy in Pakistan from the British India period through to recent years. This overview highlights the core problem of the continuing failure of Pakistani cities to develop and manage their public transport systems in such a way as to provide a high level of mobility, equity, and environmental sustainability. The paper identifies several factors, including the importance of governance, capacity building, and urban planning in providing adequate, efficient, and effective public transport in Pakistan.
\end{abstract}

\section{Introduction}

This paper highlights the core problem of the continuing failure of Pakistani cities to develop and manage their public transport systems in such a way as to provide a high level of mobility, equity, and environmental sustainability. For at least 60 years, public transport policy makers have formulated many different policies for public transport development in Pakistan. These policies make little sense in the presence of an extensive suburban railways infrastructure and high density mixed land use in urban areas. 
The purpose of this paper is to provide an historical overview of public transport policy in Pakistan from the British India period through to recent years, as viewed through the public transport planning literature. This paper outlines the discussion of public transport planning in Pakistan by (1) reviewing current literature and data, (2) reviewing the history of public transport planning and policy, and (3) listing several factors overlooked in the development of public transport in Pakistan. The data presented have been collected mainly through policy documents and published scholarly articles. The paper concludes with discussion on the importance of governance, capacity building, and urban planning in providing adequate, efficient, and effective public transport in Pakistan.

\section{Public Transportation Planning and Policy- Literature Review}

The significance of public transport for urban mobility varies in South Asian cities. Traditionally, South Asian cities are characterized by high population and employment density, mixed land use patterns, short trip length, and high shares of non-motorized transport (Thomson 1977; Tiwari 2002; Imran and Low 2003; Badami 2005; Singh 2005; Imran 2006; Haider and Badami 2007; Imran and Low 2007). However, these characteristics have been changing by spatial structure that consists of medium- to low-density housing schemes built at the edge of the city. Usually, these housing schemes are designed for the middle- to high-income groups and are accessible only by public transport and private vehicles, either cars or motorcycles. Therefore, the share of public transport and private vehicles trips is growing at the cost of non-motorized trips in South Asian cities.

Table 1 shows the percentage of total trips made on different modes of transport in Indian and Pakistani cities. The data show a large share of public transport trips in Indian cities as compared to trips made by private vehicles. On the other hand, shares of private vehicles trips are higher in Pakistani cities compared to public transport trips. One reason for the differences in Indian and Pakistani cities is the services of rail-based public transport in Mumbai and Kolkata and the recent opening and ongoing expansion of the Delhi metro. In contrast, Pakistani cities are served by bus- or wagon (minibus)-based public transport, which provides a very low level of service and comfort (see photos). In fact, Pakistani cities entered the 20th century with an urban tram system and suburban railway system. One hundred years later, these systems were either shut down or nearly shut down. Although a large number of non-motorized trips still exist in Lahore and Karachi 
(see Table 1), the expansion of Pakistani cities has increased the trip length for most urban residents, which makes walking and cycling less feasible than before, encouraging a continuous shift from non-motorized to motorized modes. In this situation, public transport can provide high-quality services for urban populations at a much lower cost than a system devoted to private motorized transport and road expansion. Almost no attention is paid to the ways and means by which the demand for motorized transport could be met by improving the quality of public transport. Therefore, in the presence of a low level of public transport services, middle- and higher-income people living in larger cities prefer private vehicles, either motorcycle or car, for travel. There is an argument that public transport trips are declining or static with popular demand or aspirations for private vehicles. An alternative view is that the lack of investment in public transport and ill-considered replacement of trams and trains with diesel buses have accelerated the move away from public transport. The historical narratives presented by Imran (2006) confirm this alternative view.

Table 1. Modal Split in South Asian Cities

\begin{tabular}{lccc}
\hline Cities & \multicolumn{3}{c}{ Total Trips } \\
\hline Private & $\begin{array}{c}\text { Public } \\
\text { Transport (\%) }\end{array}$ & $\begin{array}{c}\text { Non-Motorized } \\
\text { Transport (\%) }\end{array}$ \\
\hline Lahore & 24 & 16 & 60 \\
Karachi & 27 & 23 & 50 \\
Delhi & 18 & 40 & 42 \\
Mumbai & 18 & 60 & 22 \\
Kolkata & 5 & 78 & 17 \\
\hline
\end{tabular}

Sources: Traffic Engineering and Transport Planning Agency (TEPA) and Japan International Cooperation Agency (JICA), 1992 (Lahore); Malik 2004 (Karachi); World Bank 2002 (other Indian cities).

Numerous factors have contributed to the upward trend of private vehicle use and the declining or static role of public transport in most cities. The most important factor is continuous investment in roads, which left few or no funds for public transport provision in most cities of the developing world. For example, Howe (1996) reported how the heavy investment in roads in Bangladesh has become a threat to the social and natural environment. Badami (2005) mentioned that urban transport policy in India has been biased in favor of private transport 


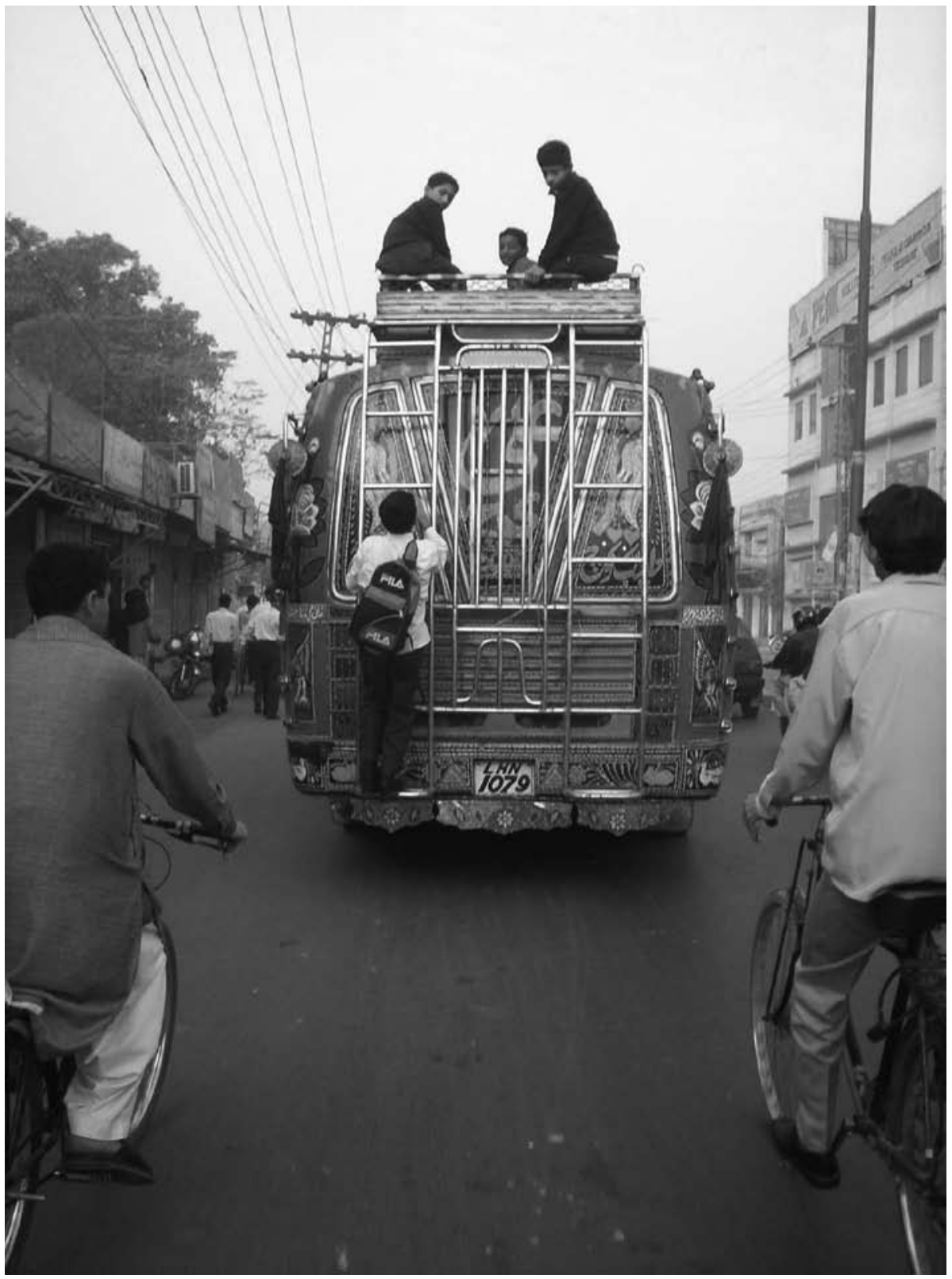

Bus-based Public Transport in Lahore 


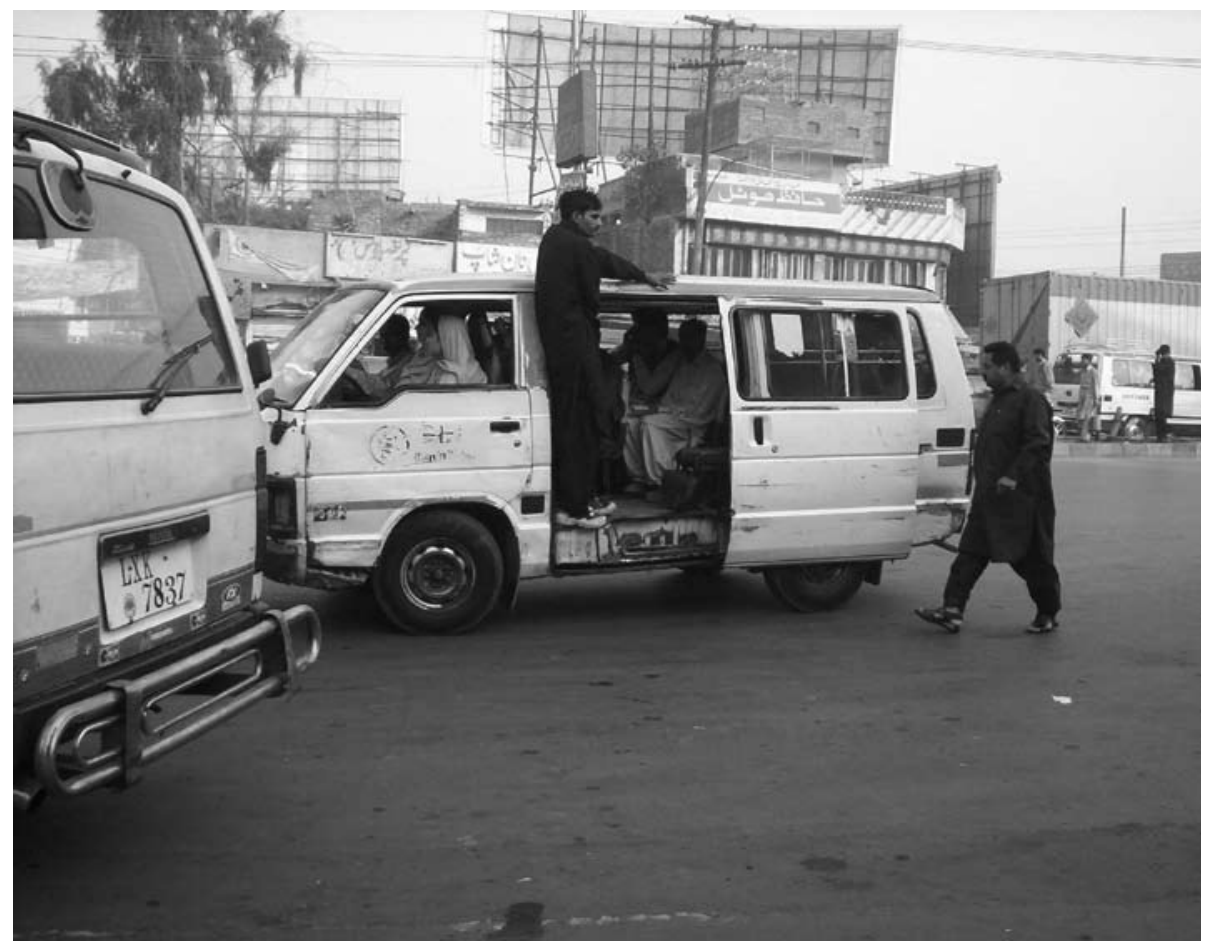

Wagon-based Public Transport in Lahore

modes. Imran and Low (2007) reported how scarce resources in Pakistani cities are deployed in road development at the expense of public transport and nonmotorized transport. They found that road investment policies are not the result of any industrial development in Pakistan, and that private vehicles did not come to Pakistani cities until after World War II happened in developed world countries. These policies developed primarily due to involvement of international development institutions and their consultants, which favored roads instead of the inherited railway that passed through most of the cities. They concluded that heavy investment in roads left no money for public transport in Pakistani cities.

Tiwari (2002) and Pucher et al. (2004) favor privatization of public transport services to generate funds to operate efficient bus services and reduce government subsidies. Tiwari (2002) found that large-scale privatization of buses in New Delhi increased the capacity of public transport. Pucher et al. (2004) reported that the privately-run services in Indian cities have higher productivity, lower costs, and 
higher revenues per bus $\mathrm{km}$ of service. They concluded that privatization does have potential to improve efficiency, but it must be accompanied by institutional capacity-building, which ensures an integrated network of public transport services. This suggestion is very difficult to implement quickly because institutional coordination and sufficient human, technical, and financial capacity among transport organizations in the developing countries is a long way off (Vasconcellos 1997; Kah 2001). Even in Europe and Australia, which have well-established institutions, the privatization and deregulation of public transport has been a significant factor behind the decline in patronage and services (Cervero 1998; Mees 2005).

Beside financial factors, there are a number of other factors that have been suggested as having an influence on the level of success of public transport systems. These include car ownership, traffic volume, parking policies, fuel cost, travel choices and capacity, urban density, urban sprawl, public transport network planning, public transport mode attractiveness and perception and governance (Cervero 1998; Vuchic 1999; Newman and Kenworthy 2000: Mees 2000; Cox 2003; Whitelegg and Haq 2003; Litman 2004; Kennedy et al. 2005). An investigation into how and to what extent these factors are contributing in the development and implementation of public transport planning and policies in Pakistani cities will be discussed in the next section.

\section{Public Transport Planning and Policy in Pakistani Cities- Historical Overview}

This section views public transport planning and policies in Pakistan in a historical context. The discussion separates the historical overview into three time frames: the British India period (up to 1947), 1947-1990, and 1991 forward. First, such an analysis provides a picture of public transport development during British India. Then, it is important to document public transport policies and development after independence from British India in 1947 because the period since then represents and symbolizes the aspirations of the newly-independent country. The discussion of 1991 forward is particularly concerned with exploring how public transport policy is accommodated within a sustainable development context. Overall, this section discloses the history of public transport planning viewed through government transport planning and policy documents and published scholarly papers. 


\section{Public Transport in British India}

The history of public transport development in British India must start from the development of the Indian railway system. In 1853, the first passenger train started from Howrah to Hoogly (currently in India) (Indian Railway Fan Club). The region that would later become Pakistan was connected by railway in 1861 by building the section between Karachi and Kotri. Up to 1865, the important cities of the now-existing Pakistan were connected by the railway to the rest of the country. The railway network in Pakistan was extended to the Afghanistan border in 1878 and to Zahidan, Iran, in 1918. In total, British India had an extensive network of railways of 41,000 miles in 1944; of this total, 8,070 miles was in the area of Pakistan (Vakil 1944).

In addition to intercity railway development and operation, the British government introduced urban public transport services (Qadeer 1983). The Karachi Tramways Act was passed in 1884, and the first steam tramway was opened for operation in 1885 along with the horse-drawn tram. Subsequently, these trams were converted to petrol engine trams in 1908. Despite this development, the tonga (horse-drawn carriages) were the only means of public transport in Pakistani cities until the late 19th century (Stalley 1972).

These urban tramways and intercity railways were supported by buses providing feeder services (Vakil 1944). Like Karachi, the city of Lahore was connected with the railway network and, in 1904, the locomotive workshops were established there to fulfill the needs of the extensive railway network. Additionally, new and wider roads were constructed in Lahore (Goulding 1924), and bus-based public transport was initiated to connect the major civic and government buildings located on the Mall Road (Rudduck 1965). During the 1920s, British elites built and settled in Model Town on the outskirts of Lahore (Glover 1999). Model town was not only designed on the principles of Ebenezer Howard's garden city, but was also managed by Howard's envisioned Model Town Co-operative Society. The Model Town Co-operative Society had not only developed its own municipal services, but also initiated a bus-based public transport service that connected the town to the rest of Lahore (Glover 1999; Russell and Anjum 1997). Overall, these public transport facilities altered the face of transport system in Pakistani cities.

Irrespective of the debate about the positive or negative aspects of public transport on the economic and social systems of British India, Thorner (1955) believed that independence in 1947 provided an opportunity for Pakistan and India to formulate new public transport policy that could be designed according to the 
newly-independent countries' needs, which were different from their colonial obligations.

\section{Public Transport in Pakistan-1947 to 1991}

In 1947, the railways constituted the most valuable capital asset of the country and were the only intercity public transport mode (Hasan 1998). At that time, Pakistan Railway (North Western Railway) carried the largest number of passengers in Pakistan (Govt. of Pakistan, National Planning Board 1957). The First Five Year Plan (1955-60) acknowledged this fact and stated:

The backbone of [West] Pakistan's transport system is a broad-gauge railway network. It is a system of main lines, one in each of five parallel river valleys, interlinked and stretching from the coast to Afghanistan and India's frontiers (Govt. of Pakistan, National Planning Board 1957: 485).

However, the plan proposed that "in [West] Pakistan a powerful railway system and growing road transport system operate side by side and should complement each other" (Govt. of Pakistan, National Planning Board 1957: 485). Accordingly, 70 per cent of the total land transport investment was made for Pakistan Railway (North Western Railway), as compared to 30 per cent for road transport during the plan period of 1955-60 (Govt. of Pakistan, National Planning Board 1957). The Road Transport Board was set up to coordinate the rail and road networks with an intercity passenger ratio of 75 and 25 per cent in the favor of railway (Govt. of Pakistan, National Planning Board 1957). It is important to note here that although resources were allocated in the favor of the railways, the plan proposed that the ratio of road to railway would increase to $25: 75$, as compared to $10: 90$ in 1947. Moreover, this plan did not propose any extension of the railway network. On the other hand, 1800 miles of new roads were planned to be constructed along with the improvement of 2000 miles of existing roads (Govt. of Pakistan, National Planning Board 1957).

In urban areas, motorized traffic was very limited until 1947 (Qadeer 1983). For example, in the city of Lahore, homes, work places, bazaars (commercial areas), and community places were located in a mixed land use pattern within a short distance. Therefore, walking was the largest mode of transport followed by tonga (horse-drawn carriage). In spite of this fact, Omni Bus was operated in the cities of Lahore and Karachi, while tramway provided services in Karachi only (Qadeer 1983). The Omni Bus (public transport) service has been a public monopoly from 
the beginning of its inception and expanded both in organization and resources over time. On the other hand, the tramway in Karachi was abolished in the early 1970s.

In 1951, the Motor Vehicle Act 1939 was amended, and the Road Transport Board was established in Punjab. The main function of the Punjab Road Transport Board was to provide efficient, adequate, economical, and coordinated public transport services in the province. In 1957, the (West) Pakistan Road Transport Board was established according to the recommendation of the First Five Year Plan (1955-60). Accordingly, the Karachi Road Transport Corporation (KRTC) was created in 1959 to be responsible to run bus-based urban public transport in Karachi.

The Second Five Year Plan (1960-65) became the first planning document in Pakistan in which the roads sector was given priority over railways by being allocated more financial resources (Govt. of Pakistan, Planning Commission 1960). The perception behind this act was stated in the plan as: '

Road transport is particularly suited to the conditions and requirements of Pakistan ... the motor vehicle is more adaptable than the railways to varying degrees of traffic intensity and permits a greater degree of speed and efficiency in haulage over short distance ... there is close relationship between the volume of transport and the level of economic activity because each depends upon the other (Govt. of Pakistan, Planning Commission 1960).

Under these beliefs, the Second Five Year Plan (1960-65) had initiated a new era of road construction in Pakistan.

The large cities of Pakistan were also inclined towards the construction of new roads and implementing road-based public transport. The Second Five Year Plan allocated considerable money to the [West] Pakistan Road Transport Board to introduce 500 new buses in its fleet for intercity public transport (Govt. of Pakistan, Planning Commission 1960). For urban transport, money was allocated to the Karachi Road Transport Corporation (KRTC) for building up a fleet of 1200 buses, procuring 700 vehicles in addition to the 500 obtained in the First Plan period (Govt. of Pakistan, Planning Commission 1960). The Second Plan took an initiative to encourage the private sector to come forward and run road based public transport. The reason for this initiative was the rapid population growth that resulted in a corresponding growth in the demand for public transport. Originally, the public sector had a monopoly on public transport in Pakistani cities. After the encouragement of private sector policy, private wagons started their operations 
along assigned routes to fulfill the growing demand for public transport. Initially, these services were reliable, fast, and comfortable, but they eventually became crowded and unsafe. Although many regulations existed and many promises were made over time, the situation has not been improved yet.

Moreover, the Second Five Year Plan (1960-65) supported the inclusion of the Karachi Circular Railway (KCR) as the first (and last to date) rail-based urban public transport project in Pakistan (Govt. of Pakistan, Planning Commission 1960). The KCR was planned to serve the whole of Karachi, including the periphery of the city. It was projected as a regular, cheap, and efficient transport for the residents of Karachi (Govt. of Pakistan, Planning Commission 1960). Later, some sections of the KCR were built. This service was very successful in the first 15 years; however, it started to decline due to lack of investment in the infrastructure. In city of Lahore, the Master Plan for Greater Lahore proposed a mass transit system in the form of a circular railway in 1965 to connect existing railway that passes through the city (Govt. of Punjab 1973). However, the recommendations concerning the circular railway as a mass transit system did not catch the attention of decision makers.

In the early 1970s, public transport was deregulated; this allowed the private sector to compete with public-owned bus services (Govt. of Pakistan, Planning Commission 1978). However, it was observed that public-owned bus services were given priority over private operators in the allocation of routes. In 1977, the Punjab Road Transport Corporation'(PRTC) and Punjab Urban Transport Corporation (PUTC) were established in the province of Punjab (Lahore Development Authority and World Bank/International Development Association 1980). The functions of the PRTC and PUTC were to provide an efficient, adequate, economical, and properlycoordinated system of road-based intercity and urban public transport services, respectively. PUTC was also responsible to provide bus stands; develop amenities; purchase, manufacture, maintain, and repair buses; and provide other related services in urban areas. Later, PUTC developed its own maintenance and body building workshops, central stores, offices, and a central transport training institute. Although public-owned Omni Buses were merged into PUTC, it had always been short of buses due to a lack of investment by the government and international organizations. To fulfill this deficiency, PUTC and the Volvo International Development Corporation completed a study for the Model Urban Transport System in Lahore (Volvo 1980). The PUTC-Volvo Model Transportation System project comprised transport planning, organizational restructuring, capacity building, and the provision of vehicles. This study identified different issues for an efficient 
bus-based public transport network in Lahore. It recommended a continuation of the mixed public and private bus system. As a result of this study, 350 Volvo buses were gifted by the Swedish government to Lahore. These buses were added to the fleet of PUTC.

Although Omni Buses were merged with PUTC and the Volvo buses were introduced, PUTC did not expand its fleet as required to cope with the enlarged system of routes and growing demand in Lahore. Therefore, PUTC tried to attract private sector by starting a leased buses scheme on specific routes run and managed by the private sector (LDA 1997). However, all these efforts were not successful over time and, gradually, PUTC bus services declined. Due to lack of investment, new buses were not purchased after 1989. Therefore, the public-owned bus system in Lahore managed by PUTC collapsed after being operational for a couple of years. Finally, the government disbanded the PUTC in 1998.

\section{Public Transport in Pakistan-1991 Onward}

\section{Public Transport in the National Transport Policy, 1991}

In 1991, a draft National Transport Policy was published by the National Transport Research Centre (NTRC). This policy suggested the adoption of a bus-based public transport system, as compared to a rail-based mass transit system, as the preferred urban transport model in the metropolitan cities of Pakistan (Govt. of Pakistan, NTRC 1991). This approach may have been adopted due the lack of finance available from the World Bank to implement a rail-based mass transit system. However, at the same time, heavy- and light-rail-based public transport was proposed in Lahore by the technical and financial assistance of JICA (TEPA and JICA 1992).

The NTRC transport policy also proposed that government responsibility should be limited to low-income groups by providing a sufficient number of subsidized public transport services (Govt. of Pakistan, NTRC 1991). It was argued that the introduction of low-quality public transport in urban areas would convey a negative image of government-owned transportation, ultimately discouraging the efforts towards promoting public transport. This policy also proposed that the government should encourage the private sector to provide efficient and high-quality public transport services for the middle class. Several steps were proposed to encourage the involvement of the private sector, including soft loans from banks, a reduction of custom duty, and tax incentives for the importation of vehicle spare parts. 


\section{Public Transport in the Prime Minister's Public Transport Scheme, 1991}

In 1991, the Prime Minister's Incentives Scheme to Revamp the Public Transport Scheme was initiated by the Nawaz Sharf's government (Govt. of Pakistan, Ministry of Communication 1991). This policy included incentive packages to import taxis, buses, and mini-buses for an efficient public transport system. The incentive packages included duty free imports of taxis, buses, and mini-buses; loan arrangements from banks at a 15 per cent annual interest rate; and special registration numbers for new public transport. This policy was implemented, and the public transport fleet was upgraded. However, the policy was changed after the Nawaz government left office.

\section{Public Transport in the National Conservation Strategy (Agenda 21), 1992}

The National Conservation Strategy (NCS) was the first comprehensive strategy to provide a framework for addressing the specific environmental concerns of Pakistan (Govt. of Pakistan, Environment and Urban Affairs Division and International Union for Conservation of Nature 1992). The Transport sectors received very little attention in the NCS. The strategy recognized the wider ecological consequences of transport use, and particular attention was paid to energy and air pollution problems. However, the emphasis was clearly on technical solutions to solve environmental problems associated with improving the energy efficiency of motor vehicles. Although the roles of public transport and non-motorized transport in reducing the impact on the environment were acknowledged, at the same time, fuel efficient cars were promoted by providing incentives in the form of tax and customs duty relief.

\section{Public Transport through Community-Based Welfare Organization}

In 1990s, two cities of Punjab province (Faisalabad and Lahore) conducted an innovative experiment to run public transport services by creating NGOs in collaboration with local private operators (Anjum and Russell 1997; LDA 1997). Accordingly, the Faisalabad Urban Transport Society (FUTS) was created in 1994 followed by the Lahore Transport System (LTS) in 1997. The FUTS and LTS were registered with the provincial Social Welfare Department with funding arranged from private operators. These NGOs were regulated by the law of social companies and administrated by a governing body. The governing body typically comprised concerned government officers, community representatives, transporters, and bus owners.

This governing body was developed on the basis of public-private-community participation to provide efficient public transport services in the city of Faisalabad 
and Lahore. These NGOs generated their funds through the private sector, renting existing infrastructure facilities and setting higher fares. The most interesting features of these NGOs were the setting of their own fares (without approval of the government) and enforcement. Initially, this experiment (especially in the case of FUTS) was successful in providing efficient, reliable, and decent public transport services by incorporating the private and community sectors in the decision making process. However, lack of investment by the private and public sectors in inducting new vehicles made this venture unsuccessful.

\section{The People's Train and Awami (People's) Bus Train Projects}

In 1996, under Prime Minister Benazir Bhutto's Development Programme for big cities, a mass transit project was started in the cities of Rawalpindi and Islamabad. This system was based on a rail-road mixed mode that contained an urban rail link between Rawalpindi and Islamabad connected with feeder coasters (mini buses) in Islamabad. The main objective of this service was to reduce peak-hour traffic congestion, reduce air pollution, and make use of existing railway infrastructure (Govt. of Pakistan, NTRC 1996).

Initially, the train service was designed for 6,000-8,000 commuters per day. Therefore, only three train services at the frequency of 1.5 hours in the morning peak and three train services at the frequency of 3 hours in the afternoon peak were started. However, after three months of operation, these services were reduced to four train services per day. Finally, this rail-road mass transit system was shut down due to heavy financial losses. The main reasons behind its failure were inadequate service planning, which includes the absence of feeder buses in Rawalpindi; very low frequency; lack of information about timetabling; lack of amenities on railway stations; and relatively higher fares without any time savings. Additionally, this train service caused traffic jams at the level crossing roads in Rawalpindi.

A similar kind of project, the Awami (People's) Bus Train, was started in 1989 by Ms. Bhutto's first government in Karachi, Rawalpindi, and Islamabad (Govt. of Pakistan, NTRC 1992). In this project, the National Transport Research Centre (NTRC) designed and developed a Bus Train (prime mover plus three trailers) using old discarded buses to provide high-capacity bus services at peak hours. The Awami Bus Train provided services on main corridor that had sufficient road width. Initially, this project was started in Karachi, and, after one year of operation, the Bus Train was shifted to Rawalpindi and Islamabad. The Bus Train had, for the first time, introduced an imaginary bus lane on the extreme left of the road. It was estimated that the Bus Train attracted a large number of commuters in Rawal- 
pindi and Islamabad from 1991 to 1993. This service used 45 per cent of its capacity and recovered 68 per cent of its cost from fares in two years of operation (Govt. of Pakistan, NTRC 1996). However, this service was shut down due to lack of interest from the government in providing public transport services.

\section{Public Transport in the National Integrated Transport Policy, 1998}

In 1998, the Ministry of Communications gave the mandate to the Chartered Institute of Transport (now Chartered Institute of Logistic and Transport - CILT) for preparing a draft National Integrated Transport Policy' (CILT 1998). This policy emphasized land use and transport integration to reduce the need to travel and to maximize the accessibility of public transport. However, the policy also suggested a zoning plan for different land uses with reservation of land for future urban transport infrastructure. It is now widely accepted that land use planning based on separated zones will generate more travel and reduce the viability of public transport.

\section{Public Transport in the Transport Sector Development Initiative (TSDI), 1999}

The Transport Sector Development Initiative (TSDI) was a joint effort among the Government of Pakistan, international development institutions (especially the World Bank), and the private sector to collectively develop a comprehensive transportation policy (TSDI 2001). The TSDI policies were heavily framed by a perception that privatization and deregulation of public transport would bring about more efficient and cost effective transport. In relation to privatization, the document states, "each mode should be developed according to the guidance of market forces ... the private sector should be encouraged to play its part in public transport ... a common platform of public and private sector should be established to discuss issues regarding different modes of transport ... existing laws and tax duties should be modified in favor of privatization" (TSDI 2001). It is noted that the emphasis on privatization has been found in all transport documents prepared with the collaboration of international development institutions. Later, these policies and recommendations were reproduced by the NTRC transport policy in 2001.

\section{Public Transport in the National Transport Strategy, 1999}

In 1999, the National Transport Strategy was developed by the Small and Medium Enterprise Development Authority (SMEDA), under the Federal Ministry of Industries and Production (Govt. of Pakistan, SMEDA 1999). In the presence of different transport ministries, the SMEDA national transport strategy showed the Nawaz 
government's intention to attract private investment to the road transport sector. This strategy was approved quickly by the federal government in 1999. It should be noted that all other transport documents were draft policy documents and not formally approved by the government.

Although the strategy is called the National Transport Strategy, it merely focused on the introduction of buses as the mode of urban public transport. Therefore, an institutional reform package for government organizations that enabled them to attract private investment in bus-based urban public transport was proposed. Accordingly, a franchise system of bus operation was introduced to run bus-based public transport. Therefore, favorable policies, tax incentives, and regulations were formulated to attract the private sector to invest in the franchise system of public transport. Government also encouraged commercial institutions and banks to cooperate with private investors to help the franchise system succeed.

At the same time, a SMEDA-type of a bus-based public transport policy on a franchise basis was introduced by the provincial (Punjab) Transport Department with the help of the World Bank (Meakin 1998). The goal was to phase out the aged public transport vehicles by introducing a regulated bus system owned and operated by the corporate private sector on the basis of route franchises (Govt. of Punjab 1998). The main role of government was the regulation of services; operational aspects were left to the private sector. Under this new policy, the government provided a package of incentives to attract private investment. These incentives consisted of a subsidy on the interest of loans, exemption of customs duty on the import of Compressed Natural Gas (CNG) and diesel buses, and subsidized lease of depots. In response to this policy, corporate private sectors introduced new buses on dedicated routes in various cities of Punjab. The policy was widely appreciated by public transport users due to the improved quality of public transport. Initially, this policy made a significant difference in the quality of public transport but started to decline due to lack of investment by the private sector. Over time, it was realized that the lack of institutional capacity in the government meant that it was not able to play an effective role in attracting private investment and managing and solving conflicts of franchised bus operations. As a result, the public transport franchising operations in the cities of Rawalpindi and Islamabad ended in early 2000. 


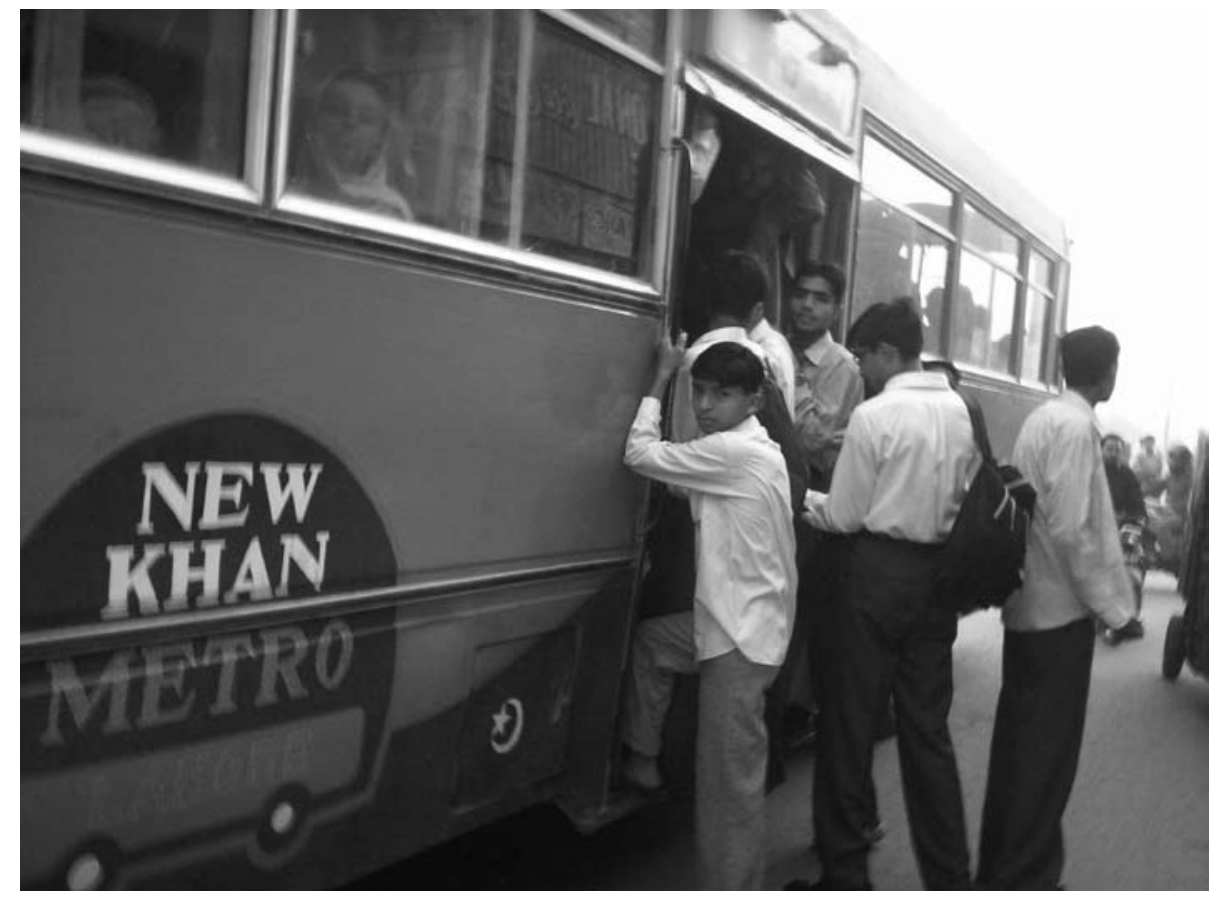

Franchised Bus in Lahore

\section{Public Transport Policies in 2000s}

In 2000s, the federal Planning Commission prepared a draft Transport Policy through an in-house process (Govt. of Pakistan, Planning Commission 2000). This document also presented a bus-based public transport system as the transport solution for metropolitan cities in Pakistan. The policy was the first to propose reserving special bus lanes at grade or grade-separated road infrastructure. The policy encouraged revitalization of the KCR as an urban rail line; the KCR had been abandoned in the late 1990s. This policy also encouraged the private sector to operate public transport.

The Ten Year Perspective Development Plan and a Medium Term Development Framework (MTDF) were prepared by the Planning Commission to be implemented between 2001 and 2011. The MTDF stated that the "development of an efficient public transport system primarily based on buses needs to be linked to mass transit systems, with light rail as an option" (Govt. of Pakistan, Planning Commission 2005). However, no money has yet been allocated for the recommended public transport system. 
The latest effort to formulate a National Transport Policy was initiated at the end of 2003, through technical assistance from the Asian Development Bank (ADB and Govt. of Pakistan, NTRC 2003). Stage one of the assistance appeared in the form of a report, "Assessment of Critical Current Transport Sector Needs," prepared by international consultants appointed by the ADB. However, this document was silent on the assessment and development of public transport in Pakistani cities. Stage two of the technical assistance, which will mainly contain sub-sector policy statements, has not yet been completed.

In early 2000, the Integrated Master Plan (2001-2021) was prepared in Lahore to guide future development (LDA 2004a). Like all previous Master Plans prepared for Lahore, this plan favored the urban road network and ignored the potential of developing public transport. Accordingly, the first five-year program for transportation development in Lahore proposed to include 94.8 percent of funding for road development, management, and maintenance and only 5.2 percent for a public transport terminal (LDA, 2004a). Clearly the plan is a road development plan, not, as it is called, a comprehensive transport plan.

In 2005, the Government of the Punjab, Transport Department, commissioned MVA Asia Ltd (international consultants) to develop a network for a mass transit system (Govt. of Punjab, Transport Department 2006). The study recommended a rail-based four-line network called the Lahore Rapid Mass Transit System (LRMTS). This rail system was proposed on the assumption that air-conditioned franchised buses introduced in the past became successful due to the rising income of the growing population. Therefore, people were willing to pay for a better service. However, no evidence was provided in support of this argument.

In 2005, the Government of Punjab prepared a Medium Term Development Framework to be implemented in 2006 to 2009. Under this framework, urban development policy objectives encompassed the establishment of an Urban Commission for preparing a comprehensive urban policy. It was proposed that a Provincial Urban Transport Policy (PUTP) would be developed to guide the future Comprehensive Urban Transport Strategy for Lahore. This strategy will be a part of the proposed Lahore City Development Strategy, which would be prepared with the technical and financial assistance of Cities Alliance. The Alliance supported cities in preparing city development strategies that "link the process by which local stakeholders define their vision for their city and its economic growth, environmental and poverty reduction objectives, with clear priorities for actions and investments" (Cities Alliance 2006: 1). The strategy would be implemented by 
the proposed Punjab Large Cities Development Policy Loan (DPL), with technical and financial assistance from the World Bank (World Bank 2006). The objectives of the proposed DPL project complement city development strategies to promote economic growth in the major cities of Punjab. This growth would be achieved through metropolitan level strategic planning, integrated infrastructure investment programs, and efficient urban service delivery. The improvement of urban transport is one of the key areas in the project.

This historical review shows that a number of policy documents were produced at the national, provincial, and local levels that addressed public transport directly or indirectly in Pakistan. These policy documents consistently affirmed the need for the development of public transport. Reasons why this development has not happened will be discussed in the next section.

\section{Discussion:}

\section{Why Did All Public Transport Policies in Pakistan Fail?}

The review of public transport planning and policy in Pakistan has provided a fascinating example of the ways in which policy paradigms have developed historically and have been gradually changed and then maintained over time. Despite the unquestionable benefits that public transport planning and policy can bring to Pakistan, there have been many shortcomings in the development and implementation of public transport policy. The primary purpose of this section is to discuss those concerns that were largely overlooked in the development of public transport policies in Pakistan.

\section{Overstating the Role of the Private Sector in Public Transport}

From the beginning, there was an issue with investing, managing, and operating public transport in Pakistani cities. Historically, the provincial governments in Pakistan have owned and operated intercity and urban public transport services. However, over the years, the government, according to the guidelines of the World Bank, advocated to encourage the private sector in operating public transport. The decline of state-owned public transport services created a vacuum that was filled by private operators in accordance with these guidelines. Initially, the market was open to private operators in parallel with public-owned public transport. However, the availability of public transport has not grown at the same rate as the population in Pakistani cities (Sohail et al. 2006). Therefore, a large number of small private operators operating Toyota 18-seater, Mazda 25-seater, and Suzuki 
12-seater wagons were permitted to fulfil this gap in a fragmented way (LDA 1997). Mees (2000) argued that an improvement of service frequency and the integration of public transport were needed for making public transport successful. It has been observed that an average frequency for small private public transport in Lahore was only four minutes, while maximum and minimum frequency observed were eight and one minutes, respectively (LDA 1997). However, the improved frequency has not provided the best service quality that was also managed in a fragmented manner. As a result, a chaotic mass of individually-owned small vehicles operated in urban areas, competing for road space. Over time, the public sector became regulators of the private operation of public transport.

Karachi Strategic Development 2020 proposed to revive and extend the Karachi Circular Railway, construct Bus Rapid Transit (BRT), and introduce Light Rail Transit (LRT) (City District Government Karachi 2007). But all these plans were conditional on investment by the private sector. The Punjab government also initiated bus-franchising schemes that offered exclusive rights to private transport operators on selected routes. The public transport operators, in turn, guaranteed a minimum quality of services on a higher fare structure decided by mutual agreement. However, after operating for few years, franchised services in many cities were closed down due to a lack of investment from the private sector and the inability of the public sector to resolve conflicts that arose from this initiative. Now, individually-owned small-vehicle-based public transport is back in the city of Rawalpindi.

In the early 1990s, a change occurred in relations between the private sector and the government. TSDI and SMEDA transport policies were developed to promote these stronger public-private relations. The government wanted more involvement by the private sector in the development and operation of public transport. The introduction of franchised public transport in different cities of Punjab province is an example of these relationships. Recently, the World Bank and ADB supported the development of the BRT system in Pakistani cities. These organizations always advocate the involvement (in terms of policy making, investment, and running public transport) by the private sector. It is important to note here that it has been the private sector that invested in and ran public transport services in Pakistan since the early 1960 s. Even now, 20,000 privately-owned buses and minibuses provide public transport services to the people of Karachi (CDGK 2007). On the other hand, public sector finance has been devoted to roads only. Over the last few decades, government has constructed 46 flyovers, 12 interchanges, and 1 
underpass in Karachi (CDGK 2007). In contrast, government always looks to the private sector for investment in public transport. International development organizations have always supported and even provided financing for roads. But such support is absent for the development of adequate public transport.

\section{Lack of Capacity among Public Transport Organizations}

Kennedy et al. (2005), in their article "The Four Pillars of Sustainable Urban Transportation," reviewed the factors contributing to best practice in urban transport. They concluded that adequate finance, infrastructure, and urban planning are important for public transport planning, but the critical requirement is effective governance. Effective governance included appropriate organizations with the necessary powers, skills, finance, and responsibilities for public transport planning. These characteristics of governance were not present in public transport organizations in Pakistan. These organizations have a long history of deficiency in professional, administrative, and financial capacity to manage public transport service planning (Imran 2006; Haider and Badami 2007).

The federal government has never denied the importance of public transport in Pakistani cities. However, the government shifted the responsibility for public transport to provincial governments in the early 1960s. On the other hand, the federal government shared the responsibility for road building with the provinces where the cost of the project was beyond the capacity of the provincial and local governments. As the provincial and local transport institutional capacity was obviously lacking in the Pakistani context, either the federal government provided finance for building roads, or the federal government built roads on their own account. In contrast, the federal government has neither provided finance for the operation of adequate public transport in urban areas nor operated by themselves or improved the capacity of the provincial transport authorities. However, the federal government helped provincial governments transfer the operational responsibility for public transport to the private sector. In the absence of human resources, coordination, research, and financial capacity of public transport institutions in Punjab, public transport has now become fully the prerogative of the private sector. The incomplete routes, high fares, fewer-than-needed buses, gender discrimination, and even absence of buses in some places are common in the urban areas of Pakistan.

Kah (2001) found through his study of privatization of urban transport in SubSaharan Africa that privatization was ineffective if a strong governance structure was not put in place. He explained that the privatization of public transport 
became extremely chaotic in the absence of a properly coordinated and regulatory institutional mechanism, as in Senegal and Gambia. Therefore, he concluded that the government has a significant role to play in defining policy, developing a national level coordination and local level implementation, accessing adequate investment, and building technical and professional capacity for public transport. This situation was not present in Pakistani cities; therefore, all policies for deregulation and privatization failed over time. For example, Haider and Badami (2007) reported that recent franchised bus operations in the cities of Islamabad and Rawalpindi were eventually closed down by the private operators due to lack of capacity in the public sector to resolve conflicts. In fact, no one knows how long franchised bus services in Lahore lasted because the institutional capacity of the provincial Transport Department to support it was not strengthened. The government and the World Bank have simply ignored this reality and have never tried to develop a capacity for the public transport organizations.

Despite the lack of capacity among public transport organizations, Pakistan has a long history of appropriate organizations with necessary skills and funding for road development. For example, the National Highway Authority (NHA) at federal level and the Communication and Works (C\&W) Department at provincial level are efficient, well-managed public organizations with dedicated funding and strong professional culture. However. there is a lack of equally competent organizations in public transport planning. This deficiency is apparent in the poor service quality of public transport in Pakistani cities. In 1977, this problem was realized, and a single authority, Punjab Urban Transport Corporation, was created to manage public transport in the province of Punjab parallel with the road organizations. The creation of a public transport corporation in Punjab contained the potential to break the path of road building dominance in transport policy. But it did not last long enough due to the unavailability of dedicated funds and a lack of interest from the government to improve its professional capacity. Therefore, it did not make an enduring impact.

Currently, overall responsibility for road development lies with the provincial C\&W departments, while public transport coordinating, planning, and monitoring lies with the Department of Transport (DoT). On the other hand, land use planning responsibilities are with the local government (City District Governments). Beside this disintegration, transport (mainly public transport) and land use development are more market driven, as per the guidelines of the World Bank, than they were in the past. A long history of the investment of the private sector in 
public transport provision has already been shown as a saga of failed experiments. Even if the private sector is willing to invest more, there is a lack of professional and management capacity among counter public organizations to make public transport successful. Therefore, a fully-capable public sector to manage public transport planning and integration of transport and land use planning does not exist at present. For that reason, it seems imperative that an effective governance system run by a new, dynamic public transport organization at metropolitan level is important, along with dedicated financial, professional, and technical capacity for managing public transport.

\section{Negligence in the Development of High-Capacity Public Transport}

The review of public transport policies showed how a new paradigm of road development emerged, despite the existence of an inherited railway network as an alternative for intercity passenger transport. In contrast with intercity transport, the policies for urban transport development were more complex in nature. The previous section demonstrated initial efforts on the establishment of both roadbased and rail-based public transport networks in the major cities of Pakistan.

The development of rail- and road-based public transport in Pakistani cities highlighted the initial emphasis of the government in national development plans, although such projects were also pursued alongside major road construction initiatives. Traditional transport planning approaches combined road projects with public transport projects. Cervero (1998), Vuchic (1999), and Newman and Kenworthy (2000) argued that investment in public transport would be combined with disinvestment in road development. Investment in both modes of transport would only make private transport successful. This is evident in the case of Pakistan where some sections of the Circular Railway in Karachi were built, operated, and then shut down. Similarly, no serious effort was made to implement the proposal of the Circular Railway in Lahore. Although JICA took the initiative in the early 1990 s to propose an LRT project in Lahore, this initiative was not implemented. On the other hand, a number of high-speed, grade-separated road projects were implemented in all the cities of Pakistan.

The current public transport system in Pakistani cities consists of buses and wagons. The government authorities, in the light of World Bank guidelines, tried to improve bus systems rather than take the initiative in rail-based public transport due to the flexibility and lower cost of bus transport However, Hass-Klau et al. (2003) believes that the high cost and inflexibility associated with a rail-based mode of travel gives it a high profile as a symbol of political commitment and financial 
security for public transport. Initially, it was declared that railways should be a backbone of public transport in Pakistan. But this policy did not last long enough due to the unavailability of finance for railway development. If the demand for public transport in Pakistan would be estimated, only rail-based public transport would have the potential to carry large numbers of passengers with higher speeds and smooth rides. The most significant potential of rail over buses is its influence on urban land by enhancing development activity around rail lines and stations. Fortunately, all Pakistani cities have an infrastructure of railways inherited from British rule. Therefore, rail-based public transport can play a catalytic role in the urban development and regeneration of Pakistani cities.

In short, Pakistani cities should not be persuaded that the growth of public transport can be managed primarily by improvements to the bus systems. Both the bus network and the rail systems are simultaneously required in Pakistan. However, the future success of public transport depends on the management of the different roles of each mode in an integrated system.

\section{Failure to Utilize High-Density Mixed Land Use Patterns}

Newman and Kenworthy (2000) are the leading advocates of the higher-density mixed land use development for the success of a public transport system. They presented a picture of a future sustainable city as high-density land use, called urban villages, served by rail-based public transport. Fortunately, the requirement of high-density mixed land use is historically present in almost all cities of Pakistan. For example, 80 percent of the population in Lahore still resides within a seven $\mathrm{km}$ radius of the city and comprises an average density of 150 to 250 persons per hectare (LDA 2004b). Luckily, the rail track in Lahore passes through these areas. However, no serious effort has been made to use high-density mixed land use and rail infrastructure for the development of rail-based public transport. In contrast, a large amount of money has been invested to build flyovers or underpasses to cross existing railway tracks in Lahore, Karachi, Faisalabad, and Rawalpindi.

The Urban Resource Centre (2001) found that the problems of public transport in Karachi were caused by its urban development policies. These policies were prepared to segregate different land use into a zone allocated for them served by a public transport system. Accordingly, lower- and middle-income people were settled into the cheap land available in the periphery of the city. On the other hand, jobs were not located near low-income populations nor was a public transport system developed. Similar policies were adopted in other cities of Pakistan. 
The fundamental message of Mitchell and Rapkin (1954) was that a transport proposal should not be evaluated only on transport criteria, but also on land use, social, and environmental grounds. It seems that these criteria have been overlooked in the provision and development of public transport. Otherwise, the land use pattern in Pakistani cities requires rail-based public transport due to its potential to transport large numbers of people quickly, reliably, comfortably, and safely in high-density areas. Therefore, it is concluded that organizations in Pakistan need to develop public transport policies that take into consideration the high-density mixed land use pattern of its cities.

In summary, all policies to provide adequate and reliable public transport in Pakistani cities have failed badly in the presence of continuous demand, high-density mixed land use patterns, and a long history of private sector involvement in the provision of public transport. Still, passengers routinely hang out from doors and windows on unreliable, unsafe, and inconvenient modes of public transport (Imran 2006; Haider and Badami 2007). The continuous decline in the quality of public transport means that it has now become the mode of transport for those who have no alternative such as car, rickshaw, or motorcycle.

\section{Conclusions and Recommendations}

The purpose of this paper was to provide a historical overview of public transport policy to identify factors responsible for the failure of the development of an efficient public transport system in Pakistan. Accordingly, overstating the role of the private sector, lack of capacity among public transport organizations, negligence in the development of high-capacity public transport, and failure to utilize existing land use patterns for the development of reliable and efficient public transport have been identified as major factors. The essence of the historical review is that once a policy path for road-based public transport and the involvement of private sector had been taken, subsequent policies and institutional arrangements supported the adopted policies and obstructed changes in policy. Overall, our discussion concludes the importance of governance, capacity-building including investment, and urban planning to provide adequate, efficient, and effective public transport in Pakistan.

The following section attempts to list some recommendations with regard to the question, how can public transport planning and policies be made more successful 
in Pakistan? While the recommendations are very general, they offer insights for future public transport policy directions for Pakistan.

- The review of public transport in Pakistan clearly showed that public transport planning became unsuccessful due to inadequacies in an overall governance structure. For example, transport planning has traditionally been divided between road organizations and public transport organizations in Pakistan. The road organizations have a full hierarchy and capacity, while the public transport organizations existed primarily at the provincial level. In the public transport area, a sophisticated institutional culture is lacking due to low financial capacity, shortage of human resources, and a lack of professional and management skills necessary to facilitate the development of public transport. Therefore, all policies to run public transport through the public sector, the semi-public sector (corporations), the deregulated private sector (privatization with fare regulation), the public-private-community sector, and franchised private sector organizations (privatization with fare deregulation) were failed over time. The creation of the National Transit Authority (NTA) as an equivalent of the National Highway Authority (NHA) along with the development of public transport organizations at the metropolitan level and accompanied by a strong and unambiguous capacitybuilding program for the above-mentioned organizations are required for the development of public transport services in Pakistan.

- The presence of mixed land use, high population and employment density, and growing needs of motorized transport use in Pakistani cities shows a potential to establish a multimodal transport system at metropolitan level. In Pakistani cities, public transport has traditionally been provided by buses, while rail-based public transport existed primarily at the intercity level. Pakistani cities have an opportunity to convert existing intercity railway into urban rail network and buses into light rail or high-capacity trolley buses with dedicated right-of-way. Pakistani cities clearly need a hierarchy of public transport modes that can carry a large to small number of passengers in different times of the day in a well-coordinated network. The multimodal public transport system has potential to play a catalytic role in the regeneration of Pakistani cities and discontinuation of the urban sprawl.

- Transport investment approaches adopted in Pakistan combine road projects with public transport and non-motorized projects. However, the research mentioned earlier shows that investment and incentives to use 
public transport would be combined with disinvestment and disincentives towards car use. The disincentive towards car use can be very effective in dense, mixed land use settings that are, fortunately, present in Pakistani cities. Therefore, strong economic controls to curb personal motor vehicle ownership and use by means of high taxes, parking costs, and traffic restraints would be required in Pakistani cities. The investment in public transport system in Pakistan demands these restrained measures to be implemented on private vehicles. Otherwise, investment towards both modes of transport would only make private transport successful.

\section{Note}

An earlier version of this paper was presented (with Ayesha Sadia) at the 13th International Planning History Society Conference in Chicago in 2008.

\section{Acknowledgments}

The author would like to acknowledge Ayesha Sadia for contributions in data collection and anonymous referees for comments. All errors are the responsibility of the author.

\section{References}

Anjum, A., and J. Russell. 1997. Public transport regulation through a government organized NGO: The Faisalabad experience in Pakistan. Transport Reviews 17(2): 105-120.

Asian Development Bank and Government of Pakistan, National Transport Research Centre. 2003. National Transport Policy, Islamabad.

Badami, M. 2005. The urban transport challenge in India: Considerations, implications and strategies. International Development Planning Review 27(2): 169-194.

Cervero, R. 1998 The Transit Metropolis: A Global Inquiry. Washington: Island Press.

Chartered Institute of Transport (CILT) Pakistan. 1998. Transport policy of Pakistan, available at http://www.pakroadusers.com/tsdi/cittp.htm\#preamble. 
Cities Alliance 2006. Available at http://www.citiesalliance.org/doc/resources/ cds/cds-guidelines/cds-gudelines-final-march06.pdf.

City District Government Karachi (CDGK). 2007. Karachi strategic development plan 2020 (draft), Karachi.

Cox, W. 2003. The illusion of transportation choice: Transit service for the elite. Victoria: The Public Purpose.

Glover, W. 1999. Making Lahore modern: Urban form and social practice in colonial Punjab 1849-1920. USA: Unpublished PhD dissertation, University of California, Berkeley.

Goulding, H. 1924. Old Lahore, reminiscences of a resident. Lahore: San-e-Meel Publications.

Government of Pakistan, Ministry of Communication. 1991. Prime Minister's public transport scheme, Islamabad.

Government of Pakistan, Ministry of Environment, Urban Affairs Division (EUAD) and IUCN. 1992. The Pakistan national conservation strategy, Islamabad.

Government of Pakistan, National Planning Board. 1957. The first five year plan (1955-60), Islamabad.

Government of Pakistan, National Transport Research Centre (NTRC). 1991. National transport policy (draft), Islamabad.

Government of Pakistan, National Transport Research Centre (NTRC). 1992. NTRC bus train, Islamabad.

Government of Pakistan, National Transport Research Centre (NTRC). 1996. The people's train (preliminary evaluation), Islamabad.

Government of Pakistan, Planning Commission. 1960. The second five year plan (1960-65), Islamabad.

Government of Pakistan, Planning Commission. 1978. The fifth five year plan (1978-83), Islamabad.

Government of Pakistan, Planning Commission. 2000. Transport policy (draft), Islamabad.

Government of Pakistan, Planning Commission. 2005. Working draft medium term development framework - MTDF (2005-10), Islamabad. 
Government of Pakistan, Small and Medium Enterprise Development Authority (SMEDA). 1999. National transport strategy (draft), Lahore.

Government of the Punjab, Housing and Physical Planning Department. 1973. Master plan for Greater Lahore. Lahore: Master Plan Project Office.

Government of the Punjab, Transport Department. 1998. Punjab urban transport sector: A promise of profit and community service, Lahore.

Govt. of Punjab, Transport Department. 2006. Terms of reference for Phase II reference design of Lahore Rapid Mass Transit System Priority (Green) Line, Lahore.

Haider, M., and M. Badami. 2007. Balancing efficiency and equity in public transit in Pakistan, in The inclusive city: Infrastructure and public services for the urban poor in Asia. Laquian, A., V. Tewari, and L. Hanley (eds). Baltimore: The Johns Hopkins University Press.

Hasan, P., 1998, Pakistan's Economy at the Crossroads: Past Policies and Present Imperatives, Karachi: Oxford University Press.

Hass-Klau C., C. Crampton, and V. Deutsch. 2003. Bus or light rail: Making the right choice. Environmental and Transport Planning, www.etphassklau.co.uk.

Howe, J. 1996. Road infrastructure investment in Bangladesh: Environment under threat? World Transport Policy and Practice 2(3): 28-33.

Imran, M., and N. Low. 2003. Time to change the old paradigm: Promoting sustainable urban transport in Lahore, Pakistan. World Transport Policy \& Practice 9(1): 32-39.

Imran, M. 2006. Identifying the institutional barriers to sustainable urban transport in Pakistan. Melbourne: Unpublished PhD dissertation, University of Melbourne, Australia.

Imran, M., and N. Low. 2007. Institutional, technical and discursive path dependence in transport planning in Pakistan. International Development Planning Review 29(3): 319-352.

Indian Railway Fan Club. http://irfca.org/faq/faq-map-1893rly.html

Kah, J. 2001. Urban transportation privatization and regulation in Sub-Saharan Africa: Problems, policies and prospects: Case studies of Senegal and the 
Gambia. New Brunswick: Unpublished PhD dissertation, State University of New Jersey.

Kennedy, C., E. Miller, A. Shalaby, H. McLean, and J. Coleman. 2005. The four pillars of sustainable urban transportation. Transport Reviews 25(4): 393-414.

Lahore Development Authority (LDA) and World Bank/IDA. 1980. Lahore urban development and traffic study, vol. 3-Traffic engineering and management study, Lahore: LDA.

Lahore Development Authority. 1997. Integrated master plan of Lahore-Draft, Lahore: NESPAK.

Lahore Development Authority. 2004a. Integrated master plan for Lahore 2021: Volume II-analysis and proposals, Lahore: NESPAK.

Lahore Development Authority. 2004b. Integrated master plan for Lahore 2021(draft): Volume I-existing scenario, Lahore: NESPAK.

Litman, T. 2004. Evaluating public transit benefits and costs. Victoria: Victoria Transport Policy Institute.

Malik, Z. 2004. Mass transit in Karachi: Moving in a right direction. Islamabad: Presentation in Chartered Institute of Logistics and Transport, Pakistan Annual Seminar, Karachi Mass Transit Cell, City District Government Karachi.

Meakin, R. 1998. The Lahore public transport policy and institutions study. Lahore: The World Bank.

Mees, P. 2000. A very public solution: Transport in the dispersed city. Melbourne: Melbourne University Press.

Mees, P. 2005. Privatization of rail and tram services in Melbourne: What went wrong? Transport Reviews 25(4): 433-449.

Mitchell, R., and C. Rapkin. 1954. Urban traffic-A function of land use. New York: Columbia University Press.

Newman, P., and J. Kenworthy. 2000. Sustainability and cities. Washington: Island Press.

Pucher, J., N. Korattyswaroopam, and N. Ittyerah. 2004. The crisis of public transport in India: Overwhelming needs but limited resources. Journal of Public Transportation 7: 1-20. 
Qadeer, M. 1983. Lahore: Urban development in third world. Lahore: Vanguard.

Rudduck, G. 1965. Urban biographies. Karachi: Planning Commission, Physical Planning and Housing Study 19.

Russell, J., and A. Anjum. 1997. Public transport and urban development in Pakistan. Transport Reviews 17(1): 61-80.

Singh, S. 2005. Review of urban transportation in India. Journal of Public Transportation 8(1): 79-97.

Sohail, M., D. Maunder, and S. Cavill. 2006. Effective regulation for sustainable public transport in developing countries. Transport Policy 13: 177-190.

Stalley, M. 1972. Patric Geddes: Spokesman for man and the environment. New Brunswick: Rutgers University Press.

Thomson, M. 1977. Great cities and their traffic. Middlesex: Penguin Books Ltd.

Thorner, D. 1955. The pattern of railway development in India. The Far Eastern Quarterly, 14(2): 201-216.

Tiwari, G. 2002. Urban transport priorities: Meeting the challenge of socio-economic diversity in cities, a case study of Delhi, India. Cities 19(2): 95-103.

Traffic Engineering and Transport Planning Agency (TEPA) and Japan International Cooperation Agency (JICA). 1992. Comprehensive study on transportation system in Lahore: Final report. Lahore: TEPA.

Transport Sector Development Initiative (TSDI). 2001. TSDI draft policy-Consolidate transport policy for all modes, a collective effort by citizens and governments of Pakistan.

Urban Resource Centre (URC). 2001. Urban poverty and transport: A case study from Karachi. Environment and Urbanization 13(1): 223-233.

Vakil, C. 1944. Railways and roads in India. Annals of the American Academy of Political and Social Science 233:187-192.

Vasconcellos, E. 1997. The urban transportation crisis in developing countries: Alternative policies for an equitable space. World Transport Policy \& Practice 3(3): 4-10.

Volvo. 1980. Model urban transport system Lahore: Summary of findings and recommendations. Lahore. 
Vuchic, V. 1999. Transportation for livable cities. New Jersey: Rutgers.

Whitelegg, J., and G. Haq (eds.). 2003. The earthscan reader on world transport policy and practice. London: Earthscan Publications.

World Bank. 2002. India's transport sector: The challenges ahead. Washington, D.C.: The World Bank.

World Bank. 2006. Pakistan_Punjab large cities DPL project-Programme information document (PID), concept stage. Washington, D.C.

\section{About the Author}

DR. Muhammad ImRAN (m.imran@massey.ac.nz) is a lecturer in the Resource and Environmental Planning program at Massey University, New Zealand. He holds bachelor's and master's degrees in City \& Regional Planning from the University of Engineering \& Technology, Lahore; a Master of Urban Planning degree from the University of Hong Kong; and a Ph.D. from the University of Melbourne. In his Ph.D., he worked on identifying and examining institutional barriers that hinder the development, application, and implementation of sustainable urban transport policies in developing countries. His research concentrates primarily on public transport and non-motorized transport in developed and developing countries. $\mathrm{He}$ is a member of the Chartered Institute of Logistics and Transport. 